\title{
Elderly People During the Coronavirus Disease 2019 Epidemic: Selected Problems
}

\author{
Małgorzata Schlegel-Zawadzka, PhD* \\ Collegium Masoviense High School of Health Sciences, Narutowicz str. 35, 96-300 Zyrardów, Poland \\ *Corresponding author \\ Małgorzata Schlegel-Zawadzka, PhD \\ Collegium Masoviense High School of Health Sciences, Narutowicz str. 35, 96-300 Zyrardów, Poland; E-mail: m.schlegelzawadzka@gmail.com
}

Article information

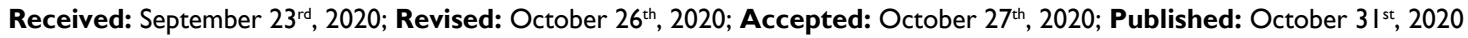

\section{Cite this article}

Schlegel-Zawadzka M. Elderly people during the coronavirus disease 2019 epidemic: Selected problems. Public Health Open J. 2020; 5(3): 68-72. doi: 10.17/40/PHOJ-5-150

\begin{abstract}
| ABSTRACT |
The coronavirus disease 2019 (COVID-19) infection mainly affected elderly patients in many countries. The care of elderly patients, especially in countries where the percentage of people over 65-years of age is significant, is an important public health problem now during the COVID-19 pandemic. In this review particular attention to the problem of proper nutrition of such patients was paid, which must be preceded by an appropriate assessment of their nutritional status. The important role of physical activity and adequate rehabilitation is highlighted. The care of elderly patients should be in line with the recommendations of the relevant scientific societies and international organizations in this respect.
\end{abstract}

Keywords

COVID-19; Elderly people; Malnutrition; Food insecurity; Nutritional risk; ESPEN recommendations; Physical activity.

\section{INTRODUCTION |}

$\mathrm{E}$ uropean Geriatric Medicine Society signed on March 23 ${ }^{\text {rd }}$, 2020, a special statement on the coronavirus disease 2019 (COVID-19) epidemic. Society informs that analysis showed that mortality rates are about $15 \%$ in contaminated subjects over 80 -years, whereas it is less than $0.5 \%$ in people below 50 -years-old. It also draws attention that "... Advanced age should not by itself be a criterion for excluding patients from specialized hospital units...". It also stresses the need for rapid rehabilitation of people who are not carriers of the virus. ${ }^{1}$

Globally as of 3.59 pm CEST, 12 September 2020, there have been 28,329,790 confirmed cases of COVID-19 including 911,877 deaths reported to World Health Organization (WHO). According to WHO COVID-19 affects different people in different ways. Most infected people will develop mild to moderate illness and recover without hospitalization. Most common symptoms are fever, dry cough and tiredness. Aches and pains, sore throat, diarrhea, conjunctivitis, headache, loss of taste and smell, a rash on skin, or discoloration of fingers or toes are considered to be fewer common symptoms. Serious symptoms are difficulty breathing or shortness of breath, chest pain or pressure and loss speech or movement. ${ }^{2}$
An important factor in any disease is the problem of the patient's nutritional status, especially when he or she is older. Malnutrition is three times more likely to cause the risk of infection and prolong patients' stay in a hospital. ${ }^{3}$ Food insecurity and lack of physical activity along with malnutrition seem to be particularly important considerations for elderly patients with COVID-19.

\section{MALNUTRITION}

Among the many reports about COVID-19 deaths there is information about the mortality of the elderly, and the reason is cited as multimorbidity. One important cause may be malnutrition of these people, which is a basic problem, regardless of the country of residence of the elderly person and increased morbidity. ${ }^{3}$ Malnutrition may be caused by reduced food intake, reduced nutrient use or increased body demand for nutrients. European Society for Clinical Nutrition and Metabolism (ESPEN) diagnoses malnutrition when person's body mass index (BMI) is below $18.5 \mathrm{~kg} / \mathrm{m}^{2}$ or by meeting two of these three criteria: unintentional weight loss $(>10 \%$ in an indefinite time period or $>5 \%$ over the last three months) combined with either a low BMI (BMI of $<20 \mathrm{~kg} / \mathrm{m}^{2}$ if $<70$-years of age, or $<22 \mathrm{~kg} / \mathrm{m}^{2}$ if $>70$-years of age) or a low fat-free mass index (FFMI) score (FFMI of $<15$ and $<17 \mathrm{~kg} / \mathrm{m}^{2}$ 
in women and men respectively). In elderly people, defined by the WHO as people over 60-years of age, there are other causes of malnutrition (Table 1).

\begin{tabular}{|c|c|}
\hline Reasons & Nature of Causes \\
\hline $\begin{array}{l}\text { Physiological } \\
\text { changes }\end{array}$ & $\begin{array}{l}\text { Changes in the mechanisms for regulating hunger and } \\
\text { satiety; reduced ability to feel thirsty; reduced ability to } \\
\text { feel taste and smell. }\end{array}$ \\
\hline Physical constraints & $\begin{array}{l}\text { Limited functioning of arms, hands and fingers; weakness } \\
\text { of gait, staying in bed, immobilization; weakness of sight; } \\
\text { ailments during chewing (inflammations, loose dentures); } \\
\text { swallowing disorders. }\end{array}$ \\
\hline Mental status & $\begin{array}{l}\text { Tangle and dementia; depression; widowhood, mourning; } \\
\text { anxiety. }\end{array}$ \\
\hline Social state & $\begin{array}{l}\text { Loneliness, isolation; poor adaptation to the care facility; } \\
\text { lack of integration. }\end{array}$ \\
\hline Health & $\begin{array}{l}\text { Acute and chronic diseases; drugs; digestive diseases } \\
\text { and gastrointestinal disorders such as nausea, vomiting, } \\
\text { diarrhoea; pain. }\end{array}$ \\
\hline Lifestyle & Unfavourable dietary habits; smoking; alcohol; inactivity. \\
\hline Chronic diseases & $\begin{array}{l}\text { Chronic heart failure; chronic lung diseases; chronic } \\
\text { polyarthritis; cancer; stroke; chronic infections; } \\
\text { gastrointestinal diseases; dementia; Parkinson's disease; } \\
\text { depression. }\end{array}$ \\
\hline Financial security & $\begin{array}{l}\text { Pension - lack of money reduces the quantity of food } \\
\text { consumed and the scope for choice and variety within } \\
\text { the diet. }\end{array}$ \\
\hline Sociali solation & $\begin{array}{l}\text { Persons living alone are reluctant to invest time in } \\
\text { cooking and eating; often they cannot lift more than } 5 \mathrm{~kg} \\
\text { shopping bag. }\end{array}$ \\
\hline
\end{tabular}

\section{FOOD INSECURITY}

Niles et $\mathrm{al}^{7}$ assessed impacts of COVID-19 on food insecurity. They conducted a statewide population-level survey using a convenience sample in Vermont (USA) from 29 March to 12 April 2020. The mean age of survey respondents was $51.5 \pm 15.6$-years (19-94-years). There was $32.3 \%$ increase in household food insecurity since COVID-19 ( $p<0.001$ ), with $35.5 \%$ of food insecure households classified as newly food insecure. Authors concluded that a job loss had three times greater odds of living in a household experiencing food insecurity (OR 3.06; 95\% CI, 2.107-4.457), and those experiencing a furlough (OR 2.89; 95\% CI, 1.856-4.485), or a lost of hours (OR 2.05; 95\% CI, 1.446-2.916) also had significantly greater odds. Two-thirds of households eating less since COVID-19 $(p<0.001)$.

\section{NUTRITIONAL RISK |}

The study conducted by Liu et $\mathrm{al}^{8}$ was to assess the nutritional risks among older patients with COVID-19. They used four nutritional risk screening (NRS) tools: NRS 2002, malnutrition universal screening tool (MUST), mini nutrition assessment shortcut (MNA-sf), and nutrition risk index (NRI). Patients diagnosed with COVID-19, older than 65-years, and hospitalized with a length of stay (LOS) more than 24 hours were enrolled in this study. COVID-19 was categorized into mild, common, severe and extremely severe in accordance with the $6^{\text {th }}$ edition of Diagnostic Standards

\section{for COVID-19.}

In multivariate regression analysis prolonged LOS, more hospital expenses, poorer appetite, and greater weight loss were significantly associated with nutritional risk. Authors concluded that the NRS 2002, MNA-sf, and NRI are useful and practical tools with respect to screening for patients with COVID-19 who are at nutritional risk. ${ }^{8}$

\section{EUROPEAN SOCIETY FOR CLINICAL NUTRITION AND METABOLISM RECOMMENDATION}

Appropriate nutritional assessment and treatment are well-documented to effectively reduce complications and improve clinical outcome various conditions, including intensive care unit (ICU) stays. The ESPEN aims at providing concise experts statements and practical guidance for nutritional management of COVID-19 patients. The recommendations are based on current ESPEN guidelines and further expert advice (Table 2).

\section{PHYSICAL ACTIVITY}

The results of a study by Coker et $\mathrm{al}^{13}$ on the effects of a 10 day bed rest healthy older people (60-85-years of age) published in 2015 showed statistically significant changes. They are losing weight, BMI, total lean mass, muscle quality, isometric and concentric $\left(60^{\circ}\right)$ knee extensions, stair ascent and descent powers and times increased, as well as floor transfer, five-minute walk, walking speed and chair stand. Authors concluded that the consequences of bed rest without appropriate countermeasures may be closely linked to inability to perform activities of daily living, increased hospitalization, and possibly lead to increased morbidity/mortality. After study all individuals participated in a 3-month rehabilitation program that enabled them to return or exceed their baseline strength and physical performance values. ${ }^{13}$

Roschel et $\mathrm{al}^{14}$ adapted from the WHO's recommendations (2010 years) physical activity for older adults (aged $>65$-years) to improve health. Isolation with social distancing, despite the later positive effects on disease spread, increase in sedentary behavior in older people and prone to frailty, sarcopenia, and chronic diseases. Authors proposed step-reduction model as better representing inactivity imposed by isolation. ${ }^{14}$

According to Italian geriatrists nutritional intervention should be combined with physical exercises. They recognized 4 phases at the recovering time: a) recover of orthostates, b) train balance and coordination of movements, c) regain muscle strength and d) start endurance training. ${ }^{15}$

\section{RECOMMENDATIONS FOR OLDER PEOPLE IN SELECTED COUNTRIES}

The recommendations announced on the website of the Polish Chief Sanitary Inspector concern the restriction of the movement of persons aged $70+$ excluding the exercise of professional activ- 


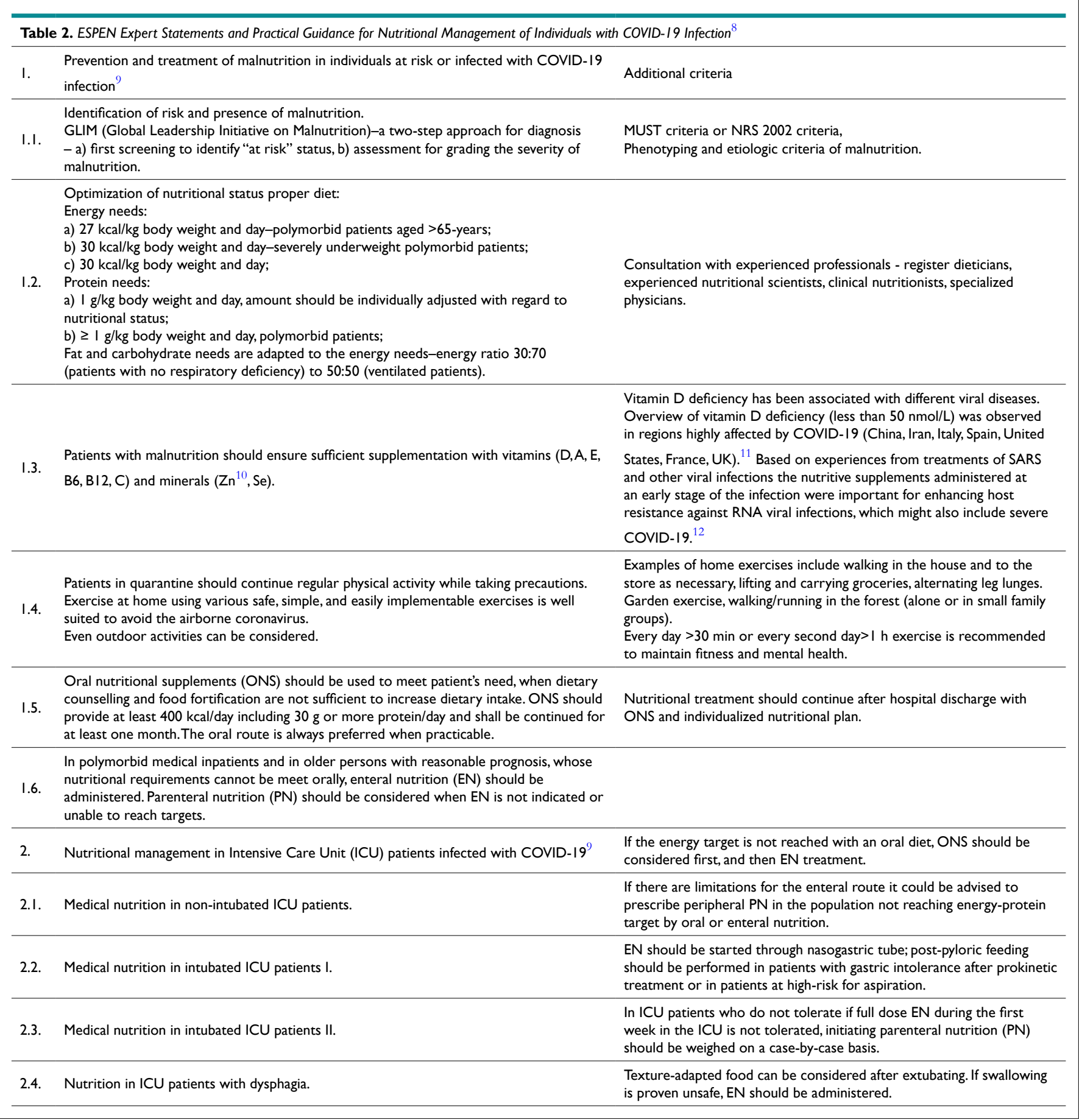

ities, meeting the necessary needs of everyday life, exercising or participating in the exercise of religious worship. Persons aged $60+$ from Monday to Friday can do food and goods shopping between 10-12 am. During this time younger persons are not allowed to buy.

Centers for Disease Control and Prevention (CDC) (USA) for people at risk of severe illness from COVID-19 limit their interactions with other people as much as possible. If they decide to engage in public activities should behave according to general rules. Persons have underlying medical conditions should continue medicines and have at least a 30-day supply of prescriptions and non-prescriptions medicines.
The French government imposed a curfew on two-thirds of the country from Friday night (23.10.2020). There are in total 47 areas of France. Greece has declared a night curfew. Spain imposes national curfew to curb COVID spread. As well as a night-time curfew, travel between regions can be banned under the emergency measures. Other European countries - Slovakia, Czech Republic, Republic of Ireland, Portugal decided about partial lockdowns. Australian government prepared special COVID-19 support line and My Aged Care. Register persons 65+ years have My Aged Care ID, which allow them for urgent home support services.

For months elderly Swedes over 70 and other at-risk 
groups have been advised to avoid going to shops, including supermarkets and pharmacies. Now they should follow the same coronavirus guidelines as the rest of population. Sweden's Public Health Agency recognized physical and mental health consequences for those groups. ${ }^{16}$

\section{PUBLIC HEALTH PLANNING APPLICATION: A COMPLEMENTARY STRATEGY}

Given the findings previously presented, it seems that a strategy that focuses only on addressing elderly people with existing malnutrition might not bring them make a full recovery. Instead we propose a complementary strategy. Keeping in mind guidelines to protect persons from a communicable disease, this strategy would include developing an interdisciplinary team consisting of a physician, a nurse, a dietician, a physiotherapist, a psychologist, a social worker, and a person who safeguards spiritual needs according to religion. Also, the team could include a case-manager for helping elderly persons sort out aspects of daily living. Collectively, this team could help meet the needs of elderly people in terms of evaluation of nutrition, material security (self-financing of the aid or the need for financing from other than one's own resources), place of residence - family environment, social welfare homes. This complementary strategy might help elderly people successfully cope with the current pandemic by practically addressing malnutrition, food insecurity, and physical activity needs.

\section{CONCLUSION}

Many of the COVID-19 symptoms indicating that elderly people develop coronavirus are superimposed on those related to the ageing process. Researchers draw attention to the need for multidisciplinary teams to care for elderly patients. An important aspect is the proper nutrition of patients, in order to prevent the malnutrition which is still frequent in healthy older people. The lack of appropriate rehabilitation of these patients does not promote full recovery. There is no proper estimation of the costs of care for the elderly during a pandemic and the psychosocial efficiencies of their departure in the cultural aspect-family or social.

\section{SOURCE OF FUNDING}

The author received no specific funding for this work.

\section{REFERENCES}

1. European Geriatric Medicine Society: Statement of the EuGMS Executive Board on the COVID-19 epidemic. Web site. https:// www.eugms.org/fileadmin/user_upload/News_Documents / News_2020/EuGMS_Statement_on_COVID-19.pdf. Accessed September 17, 2020.

2. World Health Organization (WHO). WHO CoronavirusDisease (COVID-19) WHO Dashboard. Web site. https://covid19.who. int. Accessed September 13, 2020.
3. Ljungquist O, van Gossum A, Sanz ML, de Man F. The European fight against malnutrition. Clin Nutr. 2010; 29(2): 149-150. doi: 10.1016/j.clnu.2009.10.004

4. Cederholm T, Bosaeus I, Barazzoni R, Bauer J, Van Gossum A, Klek S, et al. Diagnostic criteria for malnutrition an ESPEN Consensus Statement. Clin Nutr. 2015; 34: 335-340. doi: 10.1016/j. clnu.2015.03.001

5. World Health Organization (WHO). World Health Organization Ageing and Health. Web site. https://www.who.int/news-room/ goal-fact-sheets/detail/ageing-and-health. Accessed September 13,2020 .

6. Menebrocker C, Smoliner C. Ernährung in der Altenpflege [In: German]. Munchen, German: Elsevier GmbH Urban\&Fischer; 2013.

7. Niles MT, Bertmann F, Belarmino EH, Wenthworth T, Biehl E, Neff R. The early food insecurity impacts of COVID-19. Nutrients. 2020; 12: 2096. doi: 10.33990/nu12072096

8. Liu G, Zhang S, Mao Z, Wang W, Hu H. Clinical significance of nutritional risk screening for older adult patients with COVID-19. Eur J Clin Nutr. 2020; 74: 876-883. doi: 10.1038/s41430-020-06597

9. ESPEN expert statements and practical guidance for nutritional management of individuals with SARS-CoV-2 infection. Clin Nutr. 2020; 39: 1631-1638. doi: 10.1016/j.clnu.2020.03.022

10. De Almeida Brasiel PG. The key role of zinc in elderly immunity: a possible approach in the COVID-19 crisis. Clin Nutr ESPEN. 2020; (38): 65-66. doi: 10.1016/j.clnesp.2020.06.003

11. Ebadi M, Montano-Loza AJ. Perspective: improving vitamin D status in the management of COVID-19. Eur J Clin Nutr. 2020; 74: 856-859. doi: 10.1038/s41430-020-0661-0

12. Alexander J, Tinkov A, Strand TA, Alehagen U, Skalny A, Aasth J. Early nutrition interventions with zinc, selenium and vitamin D for raising anti-viral resistance against progressive COVID-19. Nutrients. 2020; 12: 2358. doi: 10.3390/nu12082358

13. Coker RH, Hays NP, Williams RH, Wolfe RR, Evans WJ. Bed rest promotes reductions in walking speed, functional parameters, and aerobic fitness in older, healthy adults. J GerontolA Biol Sci Med Sci. 2015; 70(1): 91-96. doi: 10.1093/gerona/glu123

14. Roschel H, Artioli GG, Gualano B. Risk of increased physical inactivity during COVID-19 outbreak in older people: A call for actions. J Am Geriatr Soc. 2020; 68(6): 1126-1128. doi: 101111/ jgs. 16550

15. Lauretani F, Ravazzoni G, Roberti MF, Longobucco Y, Adorni $\mathrm{E}, \mathrm{Grossi} \mathrm{M}$ et al. Assessment and treatment of older individu- 
als with COVID-19 multi-system disease: clinical and ethical implications. Acta Biomed. 2020; 91(2): 150-168. doi: 10.23750/abm. v91i2.9629
16. BBC NEWS. https://www.bbc.com/news/coronavirus. Accessed October 20, 2020. 